\title{
Une Welsche à Muttenz
}

\section{Julia Rippstein}

Rédactrice print et online

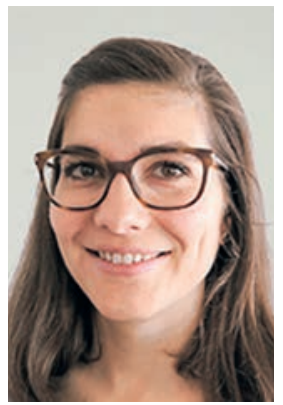

Bâtisseuse de pont. Un grand mot certes, mais je me reconnais assez bien dans ce qu'il représente. J'ai grandi en Suisse romande, toujours parlé le français à la maison, bien que mon père soit alémanique. La culture germanophone n'était jamais très loin. Mais je ne m'y identifiais pas. Comme beaucoup de Romands, outreSarine me paraissait presque... outre-Atlantique. Et le dialecte, ne m'en parlez pas. Avec les années, poussée par la curiosité (de mieux comprendre mes origines?), je me suis rapprochée de cette contrée mystérieuse où l'on prononce quatre consonnes à la suite non sans raclements gutturaux (dire que j'y arrive aujourd'hui!). Là où tout a «basculé», c'est quand j’ai étudié une année à Zurich. Une rencontre inopinée avec Cupidon et le «mal» était fait, diraient certains amis (romands) en rigolant. L'amour s'en fiche de la barrière de rösti, j'en suis la preuve. Cette relation m'a

D’incompréhensibles, les répétitifs «Isch do no frei?» ("C'est libre?») dans le train sont devenus appréciables avec le temps.

décidé, après des années d'allées et venues à travers la Suisse, à m'installer à 250 kilomètres d'où j'ai grandi, emportant dans mes cartons mon «schwiizerdütsch» teinté de français.

Avant mon "saut» outre-Sarine voilà bientôt quatre ans, quelques anecdotes m'ont forcée à opérer certains «ajustements culturels». Exit la bise aux gens que l'on rencontre pour la première fois, même si ce sont des contemporains. J'en ai ainsi surpris plus d'un! Ah, les Welsches... Les intempestifs «Isch do no frei?» ("C'est libre?») dans le train alors que le compartiment est vide, les soupers à 18 heures tapantes, la réservation obligatoire des sièges au cinéma ou encore l'incontournable Fasnacht... Et puis avec le temps, on s'y fait et on vient même à apprécier ces spécificités. Demander à quelqu'un dans le train si l'un des trois sièges vacants à côté de lui l'est réellement ne relève pas de l'excès ni de la bêtise, cela montre la prévenance des Alémaniques, leur respect pour les autres. Leur sens du collectif est nettement plus développé que chez les Romands, plutôt individualistes. Oui, ça, je l'apprécie vraiment. Et maintenant, moi aussi je demande si la place est libre.

Je mentirais en disant que rien ne me manque de la Suisse romande. Une certaine légèreté et insouciance, le quart d'heure vaudois, une petite dose d'ironie... Depuis que je suis outre-Sarine, je m'attelle à expliquer à mon entourage alémanique qui sont les Welsches: non, nous ne sommes pas français (quelle idée!), non, nous ne faisons pas l'apéro tous les soirs, et non, nous n’avons pas été passionnés par la fête fédérale de la lutte à Zoug (sans candidat romand, à quoi bon?). Nous

Les Romands? Ni Français, ni fans de lutte. Il faut parfois rappeler aux Alémaniques qu'ils ne sont pas les seuls dans la petite Suisse.

ne connaissons pas non plus vos animateurs fétiches (Giacobbo qui?!) ni les chanteurs du cru. Cela ne nous viendrait même pas à l'idée de regarder SRF (pour la TV, nous préférons les Français). Il faut donc parfois «remettre les pendules à l'heure» et rappeler aux Alémaniques que, bien que majoritaires (65\%), ils ne sont pas les seuls dans la petite Suisse. Les Romands revendiquent leur part du gâteau helvétique, qu'ils sont fiers de consommer autrement que leurs compatriotes germanophones.

Alors, Romande ou Alémanique? Un mélange des deux je dirais, même si je me sens profondément romande, ne serait-ce que par ma langue maternelle. Mais est-ce si important? Ce qui m'importe, c'est de véhiculer les valeurs d'une région vers l'autre et vice versa. Elles s'ignorent hélas encore trop, alors qu'elles auraient beaucoup à apprendre l'une de l'autre. Dans cette optique de cohésion nationale, j'apporte une contribu-

\section{Le BMS veut se rapprocher de la Romandie.}

Une tâche que j'ai, comme nouvelle rédactrice francophone, à cœur de remplir.

tion modeste mais toutefois non négligeable en tant que nouvelle rédactrice francophone au Bulletin des médecins suisses (la première, quel honneur!). J’ai d'ailleurs senti, dès le premier jour, une forme de gratitude de la part de mes collègues: une Romande parmi nous, enfin! Tel le caméléon s'adaptant à l'un et l'autre côté du Röstigraben, j'ai la belle et exigeante tâche de renforcer le pan francophone de la revue, de m'adresser aux lecteurs romands, mais aussi de montrer aux Alémaniques les projets de santé innovants qui naissent dans le «Welschland». Autrement dit, bâtir des ponts entre les deux régions linguistiques. 